\title{
Towards Satisfying Distributors in Multilevel Marketing Companies
}

\author{
Kwee-Fah Lee \\ University Tunku Abdul Rahman, Selangor, Malaysia \\ Kai-Yin Loi \\ Cosway (M) Sdn Bhd, Kuala Lumpur, Malaysia
}

\begin{abstract}
This study examined the relevant factors which affect the satisfaction of distributors towards multilevel marketing (MLM) companies in Malaysia. Six factors were investigated, which includes: method to diffuse business opportunity, perceived quality of recruiting process, perceptions of products and services, up-line support, perceived quality of training program, as well as monthly income. Results of the multiple regression analysis demonstrated that the first four factors significantly affected distributors' satisfaction. Only perceived quality of training program had no significant effect. Furthermore, one-way analysis of variance indicated that satisfaction was significantly less for distributors whose monthly income derived from MLM activities was below RM1,000 than those earning higher monthly income.
\end{abstract}

Paper type: Research paper

Keywords: Multilevel Marketing, Distributor, Job Satisfaction, Motivation, Rewards, Malaysia, Training, Up-line support, Recruitment, Business Opportunity 


\section{Introduction}

Multilevel marketing (MLM) companies have been mushrooming in many countries for several decades (Coughlan and Grayson, 1998; Brown and Peterson, 1994; Crittenden and Crittenden, 2004). MLM was once seen as the most successful business model in the 1990s (Dyer, 2001), its operations involve lower costs compared to other types of business models because it eliminates the need of channel intermediaries, namely physical retail stores (Coughlan and Grayson, 1998; Crittenden and Crittenden, 2004). The lean operation practice reduces the cost of human resource (Coughlan and Grayson, 1998). MLM companies appoint distributors instead of employing permanent sales personnel. Distributors are not permanent employees; rather, they are independent contractor who work on flexible schedule (Coughlan and Grayson, 1998).

MLM is a form of direct selling or network marketing whereby the sales of products or services are carried out by an agent or distributor to individual customers through their homes, work places, and other non-retail stores (Brodie et al., 2004). Distributors are paid for their work through incentive schemes which are based on the results achieved. They are also rewarded for the effort to introduce another distributor, who then replicates his or her work to sell the product or service to others (Coughlan and Grayson, 1998).

One of the factors that attract an individual to be part of direct-sales forces is the ability to earn commission which is proportionate to sales performance (Crittenden and Crittenden, 2004). Typically, an individual is required to buy an initial sales kit purchase in order to qualify to be a distributor of a MLM company (Keep and Nat, 2014). Fixed salary will not be provided by the company since distributors are not employees. The distributors are self-employed, independent contractor, and they earn from product sales as well as successful recruitment (Keep and Nat, 2014). When a distributor brings in another distributor, the new recruit becomes the down-line while the recruiter becomes the up-line in the same network (Lee et al., 2016). Their collective performance is achieved through purchasing products and recruitments, which generate volume to their network. The volume is a unit of bonus calculation in a reward system. At the end of each business month, the distributor will be paid based on the personal volume attained and group volume of his/her network (Keep and Nat, 2014).

Over time, the successful MLM business model attracted unethical corporations who emulated it to create illegal pyramid schemes, namely Ponzi and "get-rich-quick" schemes (Koe and Soo, 2011; Nat and Keep, 2002). These companies adopt MLM techniques such as up-line, down-line, networks, and reward plan; however, most of them do not sell products, but function through relentless recruitment. These set-ups attract recruits with over-claims about lucrative monetary reward (Keep and Nat, 2014) and yet they are merely mechanisms to shift the funds secured from the new recruit to the top of the pyramid (Nat and Keep, 2002). Ambiguous terms are often used to confuse prospects. Consequently, the boundary between legitimate MLM companies and illegal pyramid

International Journal of Management and Applied Research, 2016, Vol. 3, No. 1 
schemes is blurring, which subsequently causes scepticism and unwillingness among the public to take the risk of being a distributor despite the high returns.

For MLM companies, having numerous and effective distributors are the key to their business success. Existing distributors are required to recruit new distributors in order to grow the business. However, MLM companies have no coercive power over the distributors. Distributors are freelancers and they can stop working for the MLM companies without giving advance notice. Therefore, it is necessary to understand the factors that could motivate distributors to stay on the job. Although much literature exists for employee satisfaction, research on independent agents such as MLM distributors are rather limited. The factors affecting their satisfaction are likely to be different from regular salaried employees. Therefore, the major aim of this study is to examine the antecedents of MLM distributors' satisfaction.

\section{Literature Review}

\subsection{The Theoretical Model}

After a thorough review of the literature, Delgado (2000) developed a theoretical model to investigate the impact of recruitment and training practices on distributors' satisfaction and success in network marketing distribution channel (see Figure 1). The factors were identified to be relevant to job satisfaction and success level in MLM companies. Delgado's (2000) primary objective was to examine the effect of recruiting and training practices as an indication of the turnover of participants in MLM companies. According to his model, four factors contribute to the level of satisfaction and success of MLM distributors namely the method of diffusing business opportunity, perceived quality of recruiting practices, perceived quality of training program, and up-line involvement.

Figure 1: Model of the impact of recruiting and training practices on satisfaction and success in the distribution channel of network marketing

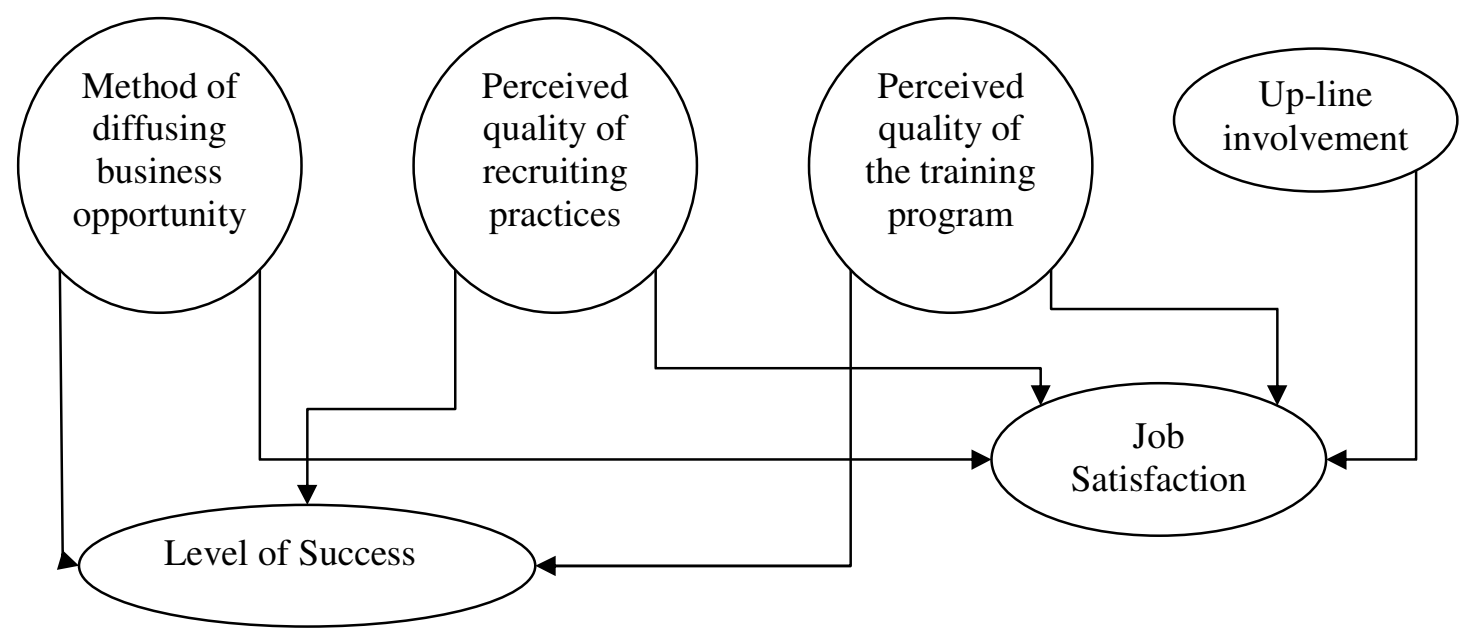

International Journal of Management and Applied Research, 2016, Vol. 3, No. 1 


\subsection{Distributors' Job Satisfaction}

Distributors are direct selling agents who function as the frontline sales force of a MLM company. A MLM company is unable terminate them even if they fail to reach the envisioned target because they are not employees. Hence, it is crucial for MLM firms to understand the motivators for distributors to meet the company objectives.

According to Comer et al. (1989), there are seven dimensions of sales representatives' job satisfaction: the distributor's attitude towards the job, workmates, supervisors, company policy and support, remuneration, and customers. Satisfied sales forces are less likely to quit their jobs (Brown and Peterson, 1994). Given the high turnover rate within the sales force (Keep and Nat, 2014) and the associated costs related to recruiting and developing talents, keeping salespeople satisfied is crucial.

\subsection{Method to Diffuse Business Opportunity}

MLM marketing is often misconceived in many countries (Coughlan and Grayson, 1998; Keep and Nat, 2011; Koe and Soo, 2011). Mainly, this is due to the deceptive pyramid scheme fraud that causing more victims than victims (Keep and Nat, 2011). Legitimate MLM companies involve a series of personal selling and networking activities, and some of these companies aim to create meaning of life for their members (Pratt, 2000). As such, many MLM companies often undertake the practices of buffering and dream building as ways to reinforce positive thinking and avoid negative thoughts about distributing (Pratt and Rosa, 2003).

One of the appealing aspects of MLM business model is that, ordinary persons can create their own networking businesses irrespective of their social status, work experiences, and educational background (Dai et al., 2011). Existing distributors recruit new distributors during their daily operations and each new recruit represent an additional set of social linkages for possible network growth (Coughlan and Grayson, 1998). The spread of wordof-mouth effect (Coughlan and Grayson, 1998; Koe and Soo, 2011) capture the notion that MLM distributors make use of personal contacts to build the multilevel distribution lines. Such relationship-based commitment to distributing stemmed from the beliefs that joining MLM companies can help to improve their lifestyle (Pratt and Rosa, 2003). Therefore, effective communication and sense-making process may allow both members and nonmembers to define a sense of belonging and redefine their purpose of life (Pratt, 2000), which influence the satisfaction level of distributors. Thus, it is posited that:

H1: The method of diffusing the business opportunity offered by the multilevel marketing company is positively related to the distributor's satisfaction.

\subsection{Perceived Quality of Recruiting Process}

According to Dai et al. (2011), a distributor should maintain good relationships with both the sponsored "up-line" and recruited "down-line". The individual distributor can attain 
success and satisfaction from cooperating and socializing with members from the same network (Sparks and Schenk, 2006). Generally, during individual coaching, the leader of the MLM network will create a vision that is strategically linked to personal career objectives and organisational goals as part of sensemaking process (Pratt, 2000; Pratt and Rosa, 2003; Sparks and Schenk, 2006). However, not all distributors are good recruiters.

The recruitment and selection process is considered as the key to business growth in the direct-selling sector (Crittenden and Crittenden, 2004) and MLM sector (Keep and Nat, 2014). According to Crittenden and Crittenden (2004), direct selling firms tend to recruit people who have interest in personal selling, with no systematic selection and formal characteristic profile regarding successful sellers. Under the philosophy of "anyone can do it", many inexperienced individuals are attracted to be members of MLM (Dai et al., 2011). One criticism of the MLM recruitment model is the inability to focus on its resources on high-performing distributors (Crittenden and Crittenden, 2004). Since distributors are expected to recruiting people and selling products at the same time, there are significant opportunity costs associated with finding downline and reaching prespecified sales targets (Coughlan and Grayson, 1998; Crittenden and Crittenden, 2004; Keep and Nat, 2014). Moreover, the distributors face fierce competition in recruiting new members with no verifiable information concerning the actual number of distributors in an area at any given time (Keep and Nat, 2014). Hence, the following is proposed:

H2: $\quad$ The perceived quality of the recruitment process in the multilevel marketing company is positively related to the distributor's satisfaction.

\subsection{Perceived Quality of Training Program}

The MLM sector is very competitive by its nature. Operating in a constantly changing market environment, the distributors should be well trained and equipped with necessary know-how (Koe and Soo, 2011). The organisational training provided by the MLM organisations is essential for both distributors and MLM companies because it not only helps distributors to develop business skills but also to recruit new members (Dai et al., 2011). Regular trainings, meetings, and mentoring programmes can improve the social ties among members (Dai et al., 2011; Pratt and Rosa, 2003; Sparks and Schenk, 2006) and potentially lead to greater level of job satisfaction. Moreover, research shows that training organised by MLM companies are positively associated with the self-efficacy of distributors in conducting network marketing businesses (Dai et al., 2011).

During training and coaching sessions, trainees are exposed to successful distributors in some of the training programmes organised by the MLM companies (Dai et al., 2011). These high-performing distributors not only share their experiences with the trainees but also spread their enthusiasm to others. Pratt and Rosa (2003) report that some MLM companies offer concrete practical suggestions regarding the issues of work-life balance. These advices are frequently shared at meetings and in coaching sessions between recruits and mentors. Thus, it is suggested that:

International Journal of Management and Applied Research, 2016, Vol. 3, No. 1 
H3: $\quad$ The perceived quality of the training program by the multilevel marketing company is positively related to the distributor's satisfaction.

\subsection{Up-line Support}

The distributor who recruits another distributor to join the MLM business is called the upline to his/her recruit who then becomes the down-line of the recruiter. In the MLM business plan, distributors are paid based on the level and generation. Their two-way support helps each other to gain higher commission. Good relationships among the member distributors in the network promote stronger ties to work towards personal and group goals (Pratt, 2000).

The relationship of an up-line distributor with his/her down-line is very important. The upline should consistently guide and support the down-line in order to achieve the potential lucrative financial incentives (Sparks and Schenk, 2006). In addition, up-line distributors are expected to provide emotional support, to share information, and offer practical suggestion to their customers and down-lines (Pratt and Rosa, 2003). Such peer support is imperative to sales force development (Dai et al., 2011; Delgado, 2000; Pratt and Rosa, 2003). The up-line distributors should also ensure the consistency of the activities and relevant planning to assist the growth of the down-line. Therefore, up-line support is expected to positively affect the satisfaction of MLM distributors:

H4: Up-line support in the multilevel marketing company is positively related to the distributor's satisfaction.

\subsection{Perception of products and services}

To a great extent, MLM distributors rely on brand appeal to sell products and services (Koe and Soo, 2011). Perceived product value is often related to the expertise of the sellers and the personal relationship between buyer and seller (Crittenden and Crittenden, 2004). Brand loyalty and repeat purchases are largely dependent on the user experience and satisfaction derived from the product quality and familiarity with the sales agents (Koe and Soo, 2011). Meeting customers' expectation is imperative to success in all businesses. As highlighted by Crittenden and Crittenden (2004: 43), "not being able to provide a customer with the right product at the right time was thought to be a deathtrap for direct selling firms". To compete with products sold in more traditional retail channels, the MLM products should be at superior standard. Additionally, some MLM companies tend to offer extra incentives to their customers, such as lifetime replacement guarantee or full refund during "cooling off" period (Crittenden and Crittenden, 2004). Such offering is hardly found in more conventional distribution channels.

Most MLM companies tend to include product or service briefing in their initial business opportunity talk to prospective distributors. According to Coughlan (2012), the sales volume of a MLM company derived from distributors and the end users (non-distributors).

International Journal of Management and Applied Research, 2016, Vol. 3, No. 1 
The end users who are satisfied with the products may become distributors especially in the cases where heavy doses of positive imagery were shared (Pratt and Rosa, 2003). Thus, attractive products are likely to attract new comers and retain existing distributors:

H5: Perception of products and services offered by the multilevel marketing company is positively related to the distributor's satisfaction.

\subsection{Monthly Income}

The compensation of MLM distributors can be divided into two categories: commission for product sales and referral bonuses (Coughlan and Grayson, 1998). The monthly income of a distributor is proportionate to his or her performance in recruiting and selling activities (Coughlan and Grayson, 1998; Crittenden and Crittenden, 2004; Keep and Nat, 2014).

Coughlan and Grayson (1998) claimed that the compensation structure affects the performance of distributors and network profitability. Typically, a distributor is rewarded for two different components in the compensation plan. Firstly, the distributor is required to maintain a monthly purchase in order to be qualified for the commission (Coughlan and Grayson, 1998). Secondly, the distributor also earns commission from the volume contributed by his/her down-line in the same network group (Coughlan and Grayson, 1998; Keep and Nat, 2014). The down-line who needs to qualify for the commission payout will be required to make a purchase for that particular month. The purchase made by him/her will contribute volume to the group. The up-line(s) from the same group will benefit from the overriding volume contributed by the down-line (Coughlan and Grayson, 1998; Keep and Nat, 2014). Failure to achieve targets implies no or little compensation (Keep and Nat, 2014).

Research indicates that financial reward as the motivation for joining MLM organisations (Comer et al., 1989; Coughlan and Grayson, 1998; Crittenden and Crittenden, 2004; Dai et al., 2011; Mswell and Sargeant, 2001). The appeal of monetary rewards to distributor is quite complex, however. As Crittenden and Crittenden (2004: 40) stated: "the promise of monetary rewards is not sufficient in and of itself". This view is consistent with the Maslow's hierarchy needs which suggest there are various types of human needs during different stages of life. On the other hand, Koe and Soo (2011) found that the reward scheme has no significant relationship with the willingness for youths to consider MLM distributor as a viable career option in Malaysia. One possible reason is the difficulty to determine the profitability of the overly complex compensation plan, in addition to job insecurity. Nevertheless, MLM distributor represents an alternative career option, especially for disadvantaged groups who lack career-specific skills and job experience (Dai et al., 2011). Thus, the following is suggested:

H6: $\quad$ There is a significant difference in distributor satisfaction across different monthly income derived from multilevel marketing activities. 


\subsection{The Proposed Research Framework}

To achieve the research objective, the following research framework is proposed. It serves as the foundation to investigate the MLM company in Malaysia. This framework is adapted from the theoretical model developed by Delgado (2000).

The model of hypothesised relationships is depicted in Figure 1. The dependent variable of this study is distributor satisfaction, with six independent variables: method to diffuse business opportunity, perceived quality of recruiting process, perceived quality of training program, perceptions of products and services, up-line support, and monthly income. The framework lays out the expected relationships between the independent and dependent variables as hypothesised in the previous sections.

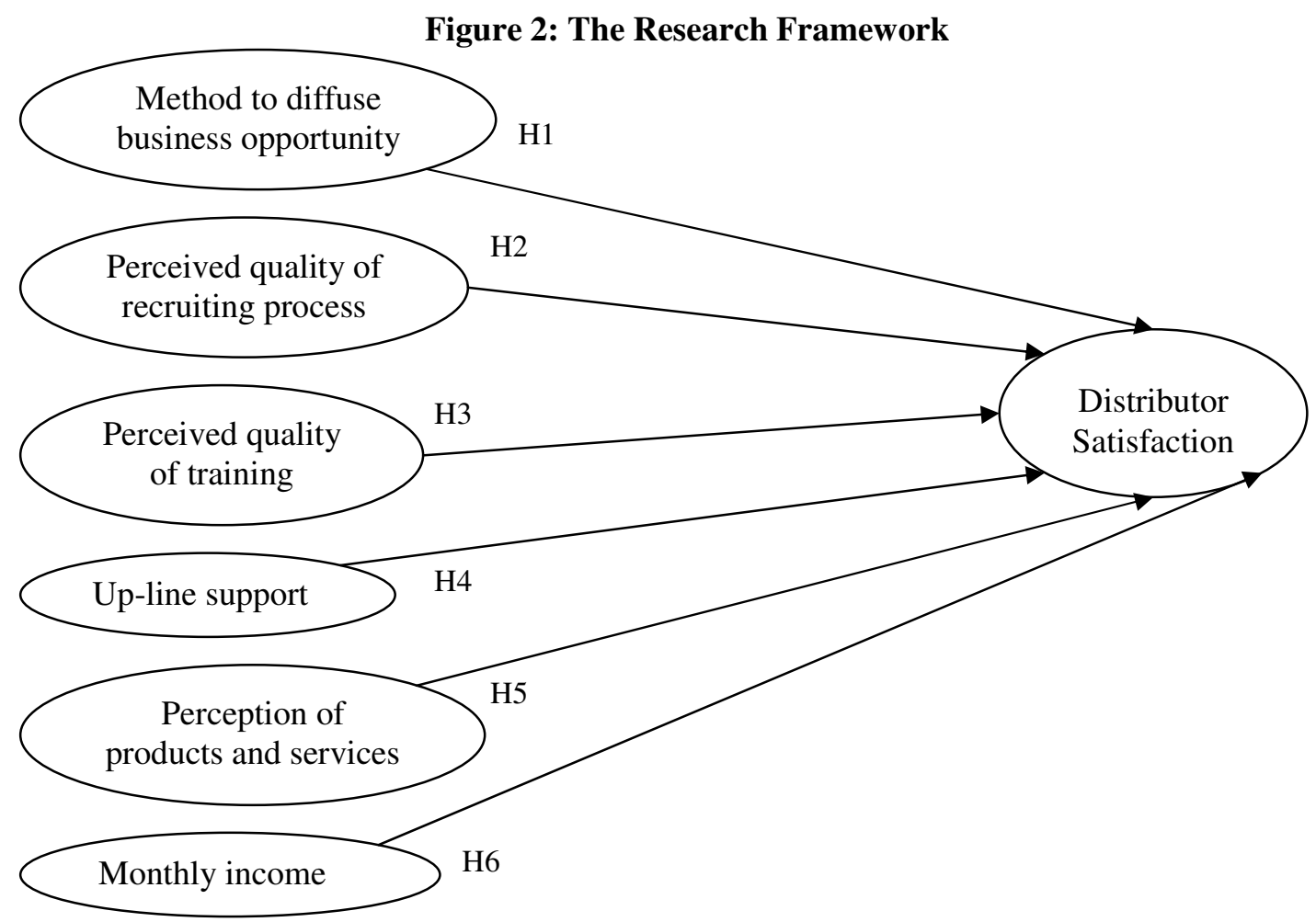

\section{Methodology}

Data was collected using self-administered questionnaires. The questionnaire items were developed in English based on the multi-item scales derived from prior research conducted by Delgado (2000), as well as Crittenden and Crittenden (2004). Five out of six constructs have been adopted from Delgado's (2000) study. They are method to diffuse business opportunity, perceived quality of recruiting process, perceived quality of training program, up-line support, and distributor satisfaction. One construct, perceptions of products and services, was taken from Crittenden and Crittenden (2004). Due to the multi-

International Journal of Management and Applied Research, 2016, Vol. 3, No. 1 
lingual various ethnic groups in Malaysia, the questionnaire was translated into Malay and Chinese languages to facilitate better comprehension and response rate among the respondents.

Firstly, pilot testing was carried out to ensure the clarity of the questionnaire items. A total of 20 questionnaires were distributed to the pilot group comprising of leaders and top management of MLM companies from the Klang Valley region. Since the pilot test did not show any misunderstanding of the questions, actual samples were then recruited. In total, 320 questionnaires were distributed online and through physical paper form. At the end of the survey period, 216 distributors replied representing a response rate of $67.5 \%$. All questionnaires were checked and found to be fit for analysis. The respondents indicated their level of agreement with each statement on a five-point Likert scale anchored by (1) Strongly Agree to (5) Strongly Disagree.

\section{Data analysis and results}

The data collected was analysed using Statistical Package for Social Science (SPSS) version 19. Statistical methods such as descriptive statistics, multiple regression and oneway analysis of variance (ANOVA) were used to explore MLM distributor satisfaction. First, descriptive statistics were used to show the distribution of the respondents' demographic profile. Next, reliability test was performed to assess the consistency and stability of the data set. Then, correlation coefficients among the variables were calculated, and distributor satisfaction was regressed on the five independent variables. Finally, ANOVA was employed to test if distributor satisfaction varies with their monthly MLM earnings.

\subsection{Descriptive Statistics}

The study respondents comprise of distributors from a prominent MLM company with its headquarters in Kuala Lumpur. Table 1 shows the demographic profile of the respondents. From a total of 216 responses, $63.9 \%$ and $36.1 \%$ were females and males respectively. Majority of the respondents were between 31 and 35 years old $(30.6 \%)$ while the next largest age group was between 36 and 40 years old (22.2\%). The youngest group made up $25.5 \%$ (21-30 years old) while the most senior group accounted for 21.8\% (41-60 years old) of the total respondents. Most respondents had received a tertiary education $(81.5 \%)$. Only $18.5 \%$ had received up to secondary or vocational school education. As for marital status, majority were married $(60.6 \%)$ while $34.7 \%$ were single, and $4.6 \%$ divorced.

In terms of monthly income from their current MLM business, majority of the respondents earned between RM1,000 and RM10,000, with an almost equal split between RM1,000 RM5,000 (30.6\%) and RM5,001-RM10,000 (29.6\%). Those earning over RM10,000 per month made up $9.7 \%$. Similarly, 9.7\% earned between RM501-RM1,000 per month while $20.4 \%$ made the least income of RM500 and below.

International Journal of Management and Applied Research, 2016, Vol. 3, No. 1 
Table 1: Demographic Profile of the Respondents

\begin{tabular}{lcc}
\hline & Frequency & Percent (\%) \\
\hline Gender $(\boldsymbol{n}=\mathbf{2 1 6})$ & 78 & 36.1 \\
Male & 138 & 63.9 \\
Female & & \\
Age & 17 & 7.9 \\
$21-25$ & 38 & 17.6 \\
$26-30$ & 66 & 30.6 \\
$31-35$ & 48 & 22.2 \\
$36-40$ & 33 & 15.3 \\
$41-50$ & 14 & 6.5 \\
$51-60$ & & \\
Education & 40 & 18.5 \\
Secondary/vocational school & 65 & 30.1 \\
Bachelor degree & 52 & 24.1 \\
Master degree & 59 & 27.3 \\
Doctoral degree & & \\
Marital status & 75 & 34.7 \\
Single & 131 & 60.6 \\
Married & 10 & 4.6 \\
Divorced & & \\
Monthly income from $\boldsymbol{M L M}$ & 44 & 20.4 \\
RM500 and below & 21 & 9.7 \\
RM501- RM1,000 & 66 & 30.6 \\
RM1,001 - RM5,000 & 64 & 29.6 \\
RM5,001 - RM10,000 & 21 & 9.7 \\
Above RM10,000 & & \\
\hline
\end{tabular}

\subsection{Reliability Analysis}

Cronbach's alpha scores were computed for each of the constructs to test for the reliability of the measured items. From table 2, the values for the six constructs range from 0.79 to 0.94 indicating very good internal consistency of the measured items since all values are well above 0.70 (Nunnally, 1978).

Table 2: Reliability Statistics

\begin{tabular}{lcc}
\hline Measures & Number of items & $\begin{array}{c}\text { Cronbach's } \\
\text { alpha }\end{array}$ \\
\hline Method to diffuse business opportunity $\left(\mathrm{X}_{1}\right)$ & 3 & 0.88 \\
Perceived quality of recruiting process $\left(\mathrm{X}_{2}\right)$ & 5 & 0.79 \\
Perceived quality of training $\left(\mathrm{X}_{3}\right)$ & 7 & 0.92 \\
Perception of products and services $\left(\mathrm{X}_{4}\right)$ & 5 & 0.91 \\
Up-line support $\left(\mathrm{X}_{5}\right)$ & 3 & 0.94 \\
Distributor satisfaction $(\mathrm{Y})$ & 5 & 0.93 \\
\hline
\end{tabular}

International Journal of Management and Applied Research, 2016, Vol. 3, No. 1 


\subsection{Hypotheses Testing}

Multiple regression analysis was employed to test for the relationships between the five independent variables and distributor satisfaction. As shown in table 3, four coefficients have positive signs as expected. Thus, the results indicate that there is a positive relationship between the four independent variables and the dependent variable. The findings suggest that distributors' satisfaction is largely dependent upon these four tested variables. Therefore, they are the best determinants of distributor's satisfaction.

Table 3: Results of Multiple Regression Analysis

\begin{tabular}{lrrrrr}
\hline Model & Sum of Squares & df & Mean Square & F & Sig. \\
\hline Regression & 21.591 & 5 & 24.318 & 93.246 & .000 \\
& & & & & \\
Residual & 54.767 & 210 & .261 & & \\
Total & 176.358 & 215 & & & \\
Variables in the Model & & & & & \\
\hline & & $\boldsymbol{\beta}$ & Std. $\boldsymbol{\beta}$ & $\mathbf{t}$ & Sig. \\
\hline Constant & -.277 & & -2.045 & .042 \\
Business opportunity $\left(\mathrm{X}_{1}\right)$ & .375 & .350 & 5.343 & .000 \\
Quality of recruiting $\left(\mathrm{X}_{2}\right)$ & .290 & .247 & 4.156 & .000 \\
Product $\left(\mathrm{X}_{4}\right)$ & .203 & .174 & 2.927 & .004 \\
Upline $\left(\mathrm{X}_{5}\right)$ & .114 & .132 & 2.828 & .005 \\
Excluded Variable in the Model & & & & \\
PQTra $\left(\mathrm{X}_{3}\right)$ & & .115 & .102 & 1.289 & .199 \\
\hline
\end{tabular}

The coefficient of determination, $\mathrm{R}^{2}$, of 0.689 indicates that close to $70 \%$ of the variance in distributor satisfaction is explained by the four variables. The $\mathrm{F}$ ratio has a value of 93.246 and significance at 0.000 . Thus, it can be concluded that the regression model employed in this study is unlikely to be a chance occurrence and can be considered significant.

The t-statistic was utilized to test if the five independent variables contributed to the dependent variable, distributor satisfaction. For this study, when the t-value of an independent variable is found to be significant at the 0.05 level, the variable is considered in the model. From table 3, it can be observed that four out of five independent variables are significant $(\mathrm{p} \leq .05)$ in the regression model. The model is presented as following:

$\mathrm{Y}=-0.277+0.375 \mathrm{X}_{1}+0.290 \mathrm{X}_{2}+0.203 \mathrm{X}_{4}+0.114 \mathrm{X}_{5}$

where:

$\mathrm{Y}=$ distributor satisfaction

$\mathrm{X}_{1}=$ method of diffusing business opportunity

$\mathrm{X}_{2}=$ perceived quality of recruiting process

$\mathrm{X}_{4}=$ perception of products and services

$\mathrm{X}_{5}=$ up-line support

International Journal of Management and Applied Research, 2016, Vol. 3, No. 1 
The partial correlation coefficient, $\beta$, shows the impact. The variable with the largest impact is "method of diffusing business opportunity" $(\beta=.375)$ followed by "perceived quality of recruiting process" $(\beta=.290)$, "perception of products and services" $(\beta=.203)$, and "up-line support" $(\beta=.114)$.

The standardized coefficient (Std. $\beta$ ) denotes the relative importance of each independent variable. The findings suggest that "method of diffusing business opportunity" (Std. $\beta=$ $.350)$ is the most important factor that explains MLM distributors' satisfaction. This is followed by "perceived quality of recruiting process" (Std. $\beta=.247$ ), "perception of products and services" (Std. $\beta=.174)$, and "up-line support" (Std. $\beta=.132)$.

\subsection{Differences in Monthly Income}

One-way analysis of variance (ANOVA) was carried out to examine the impact of monthly income on distributor satisfaction. The respondents were divided into three groups based on their monthly income earned from MLM companies. They comprise of Group 1 (below RM1,000), Group 2 (RM1,000 - RM5,000) and Group 3 (above RM5,000).

Levene's test was conducted to check for the homogeneity of variances in the three groups. Table 4 displays the results. Since the significance level of .186 is more than .05 , the assumption of homogeneity of variances is not violated. It indicates that the variance in scores is the same for each of the groups.

Table 4: Levene's Test

\begin{tabular}{lrrr}
\hline Levene Statistic & df1 & df2 & Sig. \\
\hline 1.693 & 2 & 213 & .186 \\
\hline
\end{tabular}

The results of the ANOVA test is shown in table 5. As seen, there is a statistically significant difference at the $\mathrm{p}<.05$ level in satisfaction scores for the three income groups: $\mathrm{F}(2,213)=10.2, \mathrm{p}=.000$.

Table 5: One-way Analysis of Variance (ANOVA)

\begin{tabular}{lccccc}
\hline & Sum of Squares & df & Mean Square & F & Sig. \\
\hline Between Groups & 15.355 & 2 & 7.677 & 10.157 & .000 \\
Within Groups & 161.004 & 213 & .756 & & \\
Total & 176.358 & 215 & & & \\
\hline
\end{tabular}

Consequently, post-hoc tests were conducted to determine where the exact differences between groups occur. The results are presented in table 6. Post-hoc comparisons using the Tukey HSD test indicate that the mean score for Group $1(\mathrm{M}=2.86, \mathrm{SD}=0.88)$ was significantly different from Group $2(\mathrm{M}=2.35, \mathrm{SD}=0.97)$ and Group $3(\mathrm{M}=2.24, \mathrm{SD}=$ 0.78). Group 2 did not differ significantly from Group 3. These findings imply that when income is at the lowest level, the distributor will be significantly less satisfied than those with higher earnings.

International Journal of Management and Applied Research, 2016, Vol. 3, No. 1 
Table 6: Post-Hoc Tests

\begin{tabular}{llcc}
\hline Income received (I) & Income received (J) & Mean difference (I - J) & Sig. \\
\hline$>$ RM1,000 & Between RM1,000 and RM5,000 & $.513^{*}$ & .002 \\
& Above RM5,000 & $.620^{*}$ & .000 \\
Between & Below RM1,000 & $-.513^{*}$ & .002 \\
RM1,000 and & & & \\
RM5,000 & & & \\
& Above RM5,000 & .107 & .735 \\
$<$ RM5,000 & Below RM1,000 & $-.620^{*}$ & .000 \\
& Between RM1,000 and RM5,000 & -.107 & .735 \\
\hline
\end{tabular}

\section{Discussion}

The study found that the method used to diffuse business opportunity is the most important antecedent of distributor satisfaction. A good first impression of the MLM company is essential to attract people for joining the sales force. The initial sales pitch to a prospective distributor is crucial and should be strong enough to interest the prospect. The sales pitch must also contain an appropriate weight of the opportunity offered by the MLM companies. However, the result of this study is different from Delgado (2000) which found an insignificant relationship between the method of diffusing business opportunity and satisfaction. This may be due to cultural differences since the respondents of this study were Malaysians whereas Americans were surveyed in Delgado's (2000) research.

The study also demonstrated that the perceived quality of recruiting process had an impact on distributor satisfaction, which is consistent to the study of Delgado (2000). The willingness of distributors to share information is crucial to trust-building. Moreover, most beginners in the MLM companies will commence business by sharing information with their acquaintances. A potential distributor may feel more comfortable when the "business opportunity" is shared by an acquaintance rather than a stranger. Casual sharing and/or home parties in any unplanned occasion may help the distributor in sales and recruitment which eliminates distrustful feelings. The outcome may be better than attending formal training.

In this study, perceived quality of training was found to have no significant effect on distributor satisfaction, which is inconsistent with previous works on distributor satisfaction. Dai et al. (2011) concluded that proper training and peer supports can help distributors to develop skills that are relevant to personal selling. Similarly, Delgado (2000) found that lack of training does have negative impact of distributor performance. Training is important to MLM companies because it helps to equip the distributor with the necessary technical know-how to promote their products or services more convincingly. This should satisfy distributors as training helps to increase the success rate and income. However, this does not appear to be the case here. Perhaps, this is due to one-half of the respondents who are not dependent on MLM income for a living. Although 52\% of the

International Journal of Management and Applied Research, 2016, Vol. 3, No. 1 
respondents' income came solely from MLM business, the remaining of the research participants have other sources of income. Additionally, many MLM companies conduct trainings during weekends which may also affect the family-day for some individuals. It is thus likely that the respondents have little or no free time to attend training. Although the result of this study show that training does not contribute to distributor satisfaction, it does not imply that training has no implication to performance.

With respect to perception of product and service, our results are consistent with those of previous research suggesting that perceived product value tend to influence customer satisfaction and repeat purchases (e.g., Crittenden and Crittenden, 2004, Koe and Soo, 2011) which naturally lead to distributor satisfaction. Due to the relationship-based transaction between MLM distributor and customer, the distributor faced with a double jeopardy effect (Crittenden and Crittenden, 2004). If a product fails to meet expectations of a customer, it is very likely to influence the overall customer satisfaction, which is derived from product quality and trustworthiness of the distributor. By contrast, highquality products allow MLM distributors to sell effortlessly. Moreover, satisfied customers are potential distributors. Existing distributors are likely to be loyal consumers who have made purchases even before having prior knowledge of the product/service due to the variety and uniqueness of the offerings (Kustin and Jones, 1995).

Consistent with the study of Delgado (2000), our results also show that up-line support is positively related to distributor satisfaction. Support groups and mentoring programmes are likely to be effective means of helping distributors to sustain good performance (Crittenden and Crittenden, 2004; Dai et al., 2011; Pratt and Rosa, 2003). This study also suggests that up-line support can have influential implications on both job satisfaction and performance. Some MLM companies often emphasise that distributing is a way of making new friendship and use familial labels to build long-lasting relationships (Pratt and Rosa, 2003). By its very nature, multilevel marketing is relationship based (Koe and Soo, 2011). It is thus important for MLM companies to maintain long-term relationship among and between up-lines and down-lines.

Finally, the results suggest that the higher the income of the distributor, the greater the satisfaction of the distributor. This finding is consistent with existing studies which show that monetary reward is one of the key factors for joining MLM organisations (Comer et al., 1989; Coughlan and Grayson, 1998; Crittenden and Crittenden, 2004; Dai et al., 2011; Mswell and Sargeant, 2001). Therefore, MLM companies should create a compensation system that effectively balances the incentives for distributors to recruit and sell at the same period of time. As Coughlan and Grayson (1998) stated: "any distributor recruiting and selling in a network marketing firm is always either directly or indirectly competing against other distributors in the network for both sales and new distributor recruits". Vast majority of distributers in MLM companies receive no compensation due to failure to meet sales targets (Keep and Nat, 2014). The distributors may leave if their financial needs are not met. Since intention to leave has been consistently found to be negatively related to job satisfaction (Brown and Petterson, 1994), it is imperative that MLM

International Journal of Management and Applied Research, 2016, Vol. 3, No. 1 
companies to make their reward schemes more transparent to solidify the legitimacy as viable career option (Koe and Soo, 2011).

\section{Conclusions}

This study has examined the antecedents which may impact upon distributor satisfaction with MLM companies. Five out of six factors were found to have significant positive influence on distributor satisfaction, these are: method to diffuse business opportunity, perceived quality of recruiting process, perceptions of products and services, up-line support, and monthly income. Perceived quality of training did not have a significant effect on distributor satisfaction.

The managerial implications of this study are as follows. First, companies need to invest more in product development. Attractive product offering is the key to attract new customers and potential distributors. Second, MLM companies should consider aligning personal career objectives with corporate goals. Such strategic alignment of individual and organisational goals can help to build organisational commitment. Third, MLM companies should design and build a compensation system that effectively balances the recruiting and selling activities. It is equally important for MLM companies to make their compensation structure more transparent and communicate on the viability of the potential monetary gain.

One limitation of this study is its generalisability. The sample of the current study came from one MLM company in one country. Multilevel analysis may be needed to investigate the dynamics between up-lines and down-lines distributors, especially in different cultural settings. Although the present study uses typical factors derived from prior research, it is possible that they did not fully capture the complexity of distributor satisfaction. Variables such as quality of communication, demographic factors, personalities, corporate identity, and brand equity would make useful contributions to the theory and practice of multilevel marketing.

\section{References}

1. Brodie, S., Albaum, G., Chen, D.F., Garcia, L., Kennedy, R., Msweli-Mbanga, P., Oksanen-Ylikoski, E., and Wotruba, T. (2004), Public Perceptions of Direct Selling: An International Perspective, Westminster: Westminster Business School, available from: http://westminsterresearch.wmin.ac.uk/2543/ [Accessed on 1 May 2016].

2. Brown, S. P. and Peterson, R. A. (1994), "The effect of effort on sales performance and job satisfaction", Journal Of Marketing, Vol. 58, No. 2, pp. 70-80.

3. Crittenden, V. L. and William F. Crittenden, W. F. (2004), "Developing the sales force, growing the business: The direct selling experience", Business Horizons, Vol. 47, No. 5, pp. 39-44. https://doi.org/10.1016/j.bushor.2004.07.007.

International Journal of Management and Applied Research, 2016, Vol. 3, No. 1 
4. Comer, J. M., Machleit, K. A. and Legace, R. R. (1989), "Psychometric assessment of a reduced version of INDSALES", Journal of Business Research, Vol. 18, No. 4, pp. 291-302. https://doi.org/10.1016/0148-2963(89)90023-4

5. Coughlan, A.T. (2012), FAQs on MLM companies. Available from http:// www.kellogg.northwestern.edu/faculty/coughlan/htm/personalpage_files/Papers/FAQs \%20on\%20MLM\%20Companies\%207-30-2012\%20FINAL.pdf [Accessed on 1 May 2016].

6. Coughlan, A.T. and Grayson, K. (1998), "Network marketing organisations: Compensation plans, retail network growth, and profitability", International Journal of Research in Marketing, Vol. 15, No. 5, pp. 401-426. https://doi.org/10.1016/S01678116(98)00014-7

7. Dai, F., Wang, K. Y. and Teo, S. T. (2011), "Chinese immigrants in network marketing business in Western host country context", International Business Review, Vol. 20, No. 6, pp. 659-669. https://doi.org/10.1016/j.ibusrev.2011.02.015

8. Delgado, H. (2000), The impact of the recruiting and training practices on the satisfaction and success in the networking marketing distribution channel (Doctoral dissertation). (UMI No. 9956514)

9. Dyer, W.G. (2001), "Network marketing: An effective business model for familyowned businesses?", Family Business Review, Vol. 14, No. 2, pp. 97-104. https://doi.org/10.1111/j.1741-6248.2001.00097.x

10. Keep, W.W. and Nat, P.J. (2014), "Multilevel marketing and pyramid schemes in the United States", Journal of Historical Research in Marketing, Vol. 6, No. 2, pp.188 210. https://doi.org/10.1108/JHRM-01-2014-0002

11. Koe, J.H.N. and Soo, W.M. (2011), "The influence of MLM companies and agent attributes on the willingness to undertake multilevel marketing as a career option among youth", Research in Interactive Marketing, Vol. 5, No. 1, pp. 50 - 70. https://doi.org/10.1108/17505931111121525

12. Kustin, R.A. and Jones, R.A.(1995), "Research note: A study of direct selling perceptions in Australia", International Marketing Review, Vol. 12, No. 6, pp. 60 - 67. https://doi.org/10.1108/02651339510102976

13. Lee, K.F., Lau, T.C., and Loi, K.Y. (2016), "Driving Distributors' Satisfaction in Multilevel Marketing Companies", Internationa Journal of Academic Research in Business and Social Sciences, Vol. 6, No. 2, pp. 105-122. https://doi.org/10.6007/IJARBSS/v6-i2/2015

14. Msweli, P. and Sargeant, A. (2001), "Modelling distributor retention in network marketing organisations", Marketing Intelligence and Planning, Vol. 19, No. 7, pp. 507 - 514. https://doi.org/10.1108/EUM0000000006215 
15. Nat, P.J. and Keep, W.W. (2002), "Marketing fraud: An approach for differentiating multilevel marketing from pyramid schemes", Journal of Public Policy and Marketing, Vol. 21, No. 1, pp. 139-151. https://doi.org/10.1509/jppm.21.1.139.17603

16. Nunnally, J.C. (1978), Psychometric theory. New York: McGraw-Hill.

17. Pratt, M. G. (2000), "The Good, the Bad, and the Ambivalent: Managing Identification among Amway Distributors", Administrative Science Quarterly, Vol. 45, No. 3, pp. 456-493. https://doi.org/10.2307/2667106

18. Pratt, M. G. and Rosa, J. A. (2003), "Transforming work-family conflict into commitment in network marketing organisations", Academy Of Management Journal, Vol. 46, No. 4, pp. 395-418. https://doi.org/10.2307/30040635

19. Sparks, J.R. and Schenk, J.A. (2006), "Socialization communication, organisational citizenship behaviours, and sales in a multilevel marketing organisation", Journal of Personal Selling and Sales Management, Vol. 26, No. 2, pp. 161-180. https://doi.org/10.2753/PSS0885-3134260204 